\title{
EDITORIAL
}

\section{Osteopontin - a biomarker for organ damage in paediatric lupus?}

Tracy A Briggs

See related research by Rullo et al., http://arthritis-research.com/content/15/1/R18

\begin{abstract}
A growing body of literature has demonstrated that the multifunctional glycoprotein osteopontin (OPN), has a role in type I interferon (IFN) production and may be involved in systemic lupus erythematosus (SLE) pathogenesis. A recent report has provided further support for this, demonstrating an association between raised baseline circulating plasma osteopontin (COPN) levels and IFN, and an elevation in COPN prior to the onset of both increased cumulative disease and endorgan damage. These associations were most marked in paediatric SLE, implying that cOPN may be a useful biomarker of disease activity in childhood lupus.
\end{abstract}

The recent report by Rullo and colleagues [1] suggesting that elevated circulating plasma osteopontin (COPN) may herald the onset of end-organ damage in paediatric systemic lupus erythematosus (pSLE) is of great interest. This is both in terms of highlighting a potential pSLE biomarker and to further strengthen the association of osteopontin (OPN) with type I interferon (IFN) induction and lupus pathogenesis.

Robust and reliable biomarkers for SLE, and PSLE in particular, are much needed, particularly as there are fewer validated disease markers in paediatric compared with adult SLE. This is despite pSLE, which represents 10 to $20 \%$ of all cases, being often more severe, with an increased likelihood of significant complications and multi-organ involvement [2]. Indeed, in the present study, $70 \%$ of the pSLE cohort had renal disease at recruitment, compared to only $17 \%$ in the adult SLE cohort [1].

Rullo and colleagues [1] demonstrated that increased cOPN at baseline was associated with antibodies to

*Correspondence: tracy.briggs@manchester.ac.uk

Genetic Medicine, Manchester Academic Health Science Centre, Central Manchester University Hospitals NHS Foundation Trust, Manchester, M13 9WL, UK double-stranded DNA $(P=0.001)$, elevated IFN alpha $(P=0.02)$ and an increased cumulative prednisolone exposure in pSLE $(P=0.01)$. A longitudinal prospective evaluation of the 42 pSLE and 23 adult SLE cases was then undertaken, which showed a positive correlation between COPN and adjusted-mean SLE disease activity index at 6 months in both the adult SLE and pSLE cohorts. Furthermore, in pSLE at the final (one year) time point cOPN was significantly $(P=0.001)$ associated with the System Lupus International Collaborating Clinics/ American College of Rheumatology damage index, thus suggesting that elevated COPN, in pSLE especially, may be a useful biomarker to signal the onset of increased disease activity and end organ damage.

OPN exists in both a secreted (sOPN) and an intracellular form (iOPN), which are produced by alternative translation initiation sites. OPN, particularly sOPN, has many reported functions and these are regulated by posttranslational modifications, particularly phosphorylation. Described functions include roles in cell adhesion, differentiation and migration, and in the regulation of apoptosis. Importantly, when considering autoimmune disease, OPN is expressed in a number of immune cells, particularly $\mathrm{T}$ cells, macrophages and dendritic cells [3-5].

The work of Cantor and colleagues [6,7] is most relevant to the demonstrated association between elevated IFN alpha and cOPN, as they described links between iOPN and IFN metabolism. In murine plasmacytoid dendritic cells, the authors demonstrated that iOPN was pivotal to IFN production following TLR9 induction with CpG [6]. Most recently, they illustrated that an IFNmediated inhibition of iOPN in dendritic cells resulted in reduced pro-inflammatory Th17 responses [7].

The relationship between OPN, IFN and pSLE is also illustrated by genetic studies. Polymorphisms in spp1, which encodes OPN, are associated with elevated IFN alpha induction in young people with SLE [8]. Furthermore, pSLE and elevated levels of IFN alpha are observed in the rare Mendelian disorder spondyloenchondrodysplasia, which occurs due to a deficiency of tartrateresistant acid phosphatase (TRAP) [9]. Interestingly, 
these patients have elevated levels of urinary phosphorylated OPN [10], perhaps indicating that a build up of activated phosphorylated OPN (due to an absence of TRAP de-phosphorylation) is responsible for the IFN signature and autoimmune phenotype observed.

The work of Rullo and colleagues [1] raises a number of potentially interesting questions that warrant further study. A larger scale investigation over a prolonged period is required to determine whether OPN can be utilized as a predictor of adverse disease outcome in SLE. In addition, this investigation further emphasises the need to determine the exact role of OPN in lupus, particularly pSLE, as this may be a future therapeutic target.

\section{Abbreviations}

cOPN, circulating plasma osteopontin; IFN, interferon; iOPN, intracellular osteopontin; OPN, osteopontin; pSLE, paediatric systemic lupus erythematosus; SLE, systemic lupus erythematosus; sOPN, secreted osteopontin; TRAP, tartrate-resistant acid phosphatase.

\section{Competing interests}

The author declares that they have no competing interests.

Published: 8 March 2013

\section{References}

1. Rullo OJ, Woo JM, Parsa MF, Hoftman AD, Maranian P, Elashoff DA, Niewold TB, Grossman JM, Hahn BH, McMahon M, McCurdy DK, Tsao BP: Plasma levels of osteopontin identify patients at risk for organ damage in systemic lupus erythematosus. Arthritis Res Ther 2013, 15:R18.

2. Ardoin SP, Schanberg LE: Paediatric rheumatic disease: Lessons from SLE: children are not little adults. Nat Rev Rheumato/ 2012, 8:444-445.

3. Shinohara ML, Jansson M, Hwang ES, Werneck MB, Glimcher LH, Cantor H: T-bet-dependent expression of osteopontin contributes to T cell polarization. Proc Natl Acad Sci U S A 2005, 102:17101-17106.
4. Kawamura K, Iyonaga K, Ichiyasu H, Nagano J, Suga M, Sasaki Y: Differentiation, maturation, and survival of dendritic cells by osteopontin regulation. Clin Diagn Lab Immunol 2005, 12:206-212.

5. Weber GF, Zawaideh S, Hikita S, Kumar VA, Cantor H, Ashkar S:

Phosphorylation-dependent interaction of osteopontin with its receptors regulates macrophage migration and activation. J Leukoc Biol 2002 , 72:752-761.

6. Shinohara ML, Lu LR, Bu J, Werneck MBF, Kobayashi KS, Glimcher LH, Cantor H: Osteopontin expression is essential for interferon-alpha production by plasmacytoid dendritic cells. Nat Immunol 2006, 7:498-506.

7. Shinohara ML, Kim JH, Garcia VA, Cantor H: Engagement of the type I interferon receptor on dendritic cells inhibits Thelper 17 cell development: role of intracellular osteopontin. Immunity 2008, 29:68-78.

8. Kariuki SN, Kirou KA, MacDermott EJ, Barillas-Arias L, Crow MK, Niewold TB: Cutting edge: autoimmune disease risk variant of STAT4 confers increased sensitivity to IFN-alpha in lupus patients in vivo. J Immuno/ 2009, 182:34-38.

9. Briggs TA, Rice GI, Daly S, Urquhart J, Gornall H, Bader-Meunier B, Baskar K, Baskar S, Baudouin V, Beresford MW, Black GC, Dearman RJ, de Zegher F, Foster ES, Francès C, Hayman AR, Hilton E, Job-Deslandre C, Kulkarni ML, Le Merrer M, Linglart A, Lovell SC, Maurer K, Musset L, Navarro V, Picard C, Puel A, Rieux-Laucat F, Roifman CM, Scholl-Bürgi S, et al: Tartrate-resistant acid phosphatase deficiency causes a bone dysplasia with autoimmunity and a type I interferon expression signature. Nat Genet 2011, 43:127-131.

10. Lausch E, Janecke A, Bros M, Trojandt S, Alanay Y, De Laet C, Hübner CA, Meinecke P, Nishimura G, Matsuo M, Hirano Y, Tenoutasse S, Kiss A, Rosa RF, Unger SL, Renella R, Bonafé L, Spranger J, Unger S, Zabel B, Superti-Furga A: Genetic deficiency of tartrate-resistant acid phosphatase associated with skeletal dysplasia, cerebral calcifications and autoimmunity. Nat Genet 2011, 43:132-137.

doi:10.1186/ar4172

Cite this article as: Briggs TA: Osteopontin - a biomarker for organ damage in paediatric lupus? Arthritis Research \& Therapy 2013, 15:1 10. 